\title{
EL «BLANQUEO CONSTITUCIONAL»Y EL TRIBUNAL CONSTITUCIONAL. COMENTARIO A LA SENTENCIA ROL No 2975-2016 Y LA VIGENCIA DE LA CONSTITUCIÓN*
}

\author{
FRANCISCO ZÚNIGGA URBINA \\ Profesor titular de Derecho Constitucional \\ Universidad de Chile. \\ fzuniga@zcabogados.cl
}

\section{AnteCedentes. Requerimiento de inCONSTitucionalidad POR EL AUTO ACORDADO DE LA CORTE SUPREMA}

Con fecha 18 de abril de 2017, el Tribunal Constitucional declaró inconstitucional el Auto Acordado de la Corte Suprema de 18 de diciembre de 2015, mediante el cual se estableció que la limitación de edad instituida en el artículo 80 de la Constitución Política rige también para los jueces de policía local por vulnerar el derecho de igualdad ante la ley.

Los requerimientos fueron planteados por distintos jueces de policía local de diversas comunas del país, que solicitaron que se declarara la inconstitucionalidad respecto del Auto Acordado de la Corte Suprema, publicado en el Diario Oficial de 16 de enero de 2016, que hace aplicable a ellos el límite de 75 años de edad para permanecer en sus cargos por vulnerar diversos derechos fundamentales como la libertad de trabajo, el derecho de propiedad, la libertad económica, el derecho a la igualdad y no discriminación arbitraria, entre otros.

El texto del Auto Acordado dispone sobre la permanencia de los jueces de policía local, en particular sobre la temática del límite de edad fijado a los jueces en el artículo 80 de la Constitución Política de la República que regula la cesación del cargo a los 75 años de edad, inamovilidad relativa que compartirían los jueces de policía local con aquellos que forman parte del Poder Judicial, por lo que al cumplir determinada edad los jueces han de cesar en el cargo por declaración de vacancia. En resumidas cuentas, la Corte Suprema a través del

\footnotetext{
${ }^{*}$ Comentario jurisprudencial recibido el 17 de mayo de 2017 y aprobado el 7 de septiembre de 2017.
} 
Auto Acordado considera plenamente aplicable a los jueces de policía local la limitación etaria dispuesta por la Constitución interpretando los artículos $3^{\circ}$ y $8^{\circ}$ de la Ley No 15.231 Orgánica de los Jueces de Policía Local que dispone que deben cumplir con los requisitos para ser juez de letras; y artículo 144 letra c y artículo 147 letra b de la Ley No 18.883 sobre Estatuto Administrativo Municipal que establece que hay declaración de vacancia si el funcionario pierde los requisitos de ingreso a la municipalidad. La Corte Suprema consideró además que la inamovilidad indefinida desapareció con la Constitución de 1980 al establecer el límite de 75 años de edad, regla de la que no estarían al margen los jueces de policía local.

Más allá del asunto propio que trata la sentencia del Tribunal Constitucional respecto a la constitucionalidad del Auto Acordado sobre aplicación de la limitación etaria a los jueces de policía local, lo que nos convoca a escribir estas líneas es el análisis realizado por el Tribunal sobre la vigencia de la Constitución de 1925 y su aplicación en período de anormalidad institucional con base en la referencia que hace el artículo $8^{\circ}$ de la Ley $N^{\circ} 15.231$ a los artículos 84,85 y 86 de la Carta Fundamental de 1925. Esta cuestión es un obiter dicta, accesoria a lo discutido en la sentencia, pero a mi juicio muy relevante en términos históricopolíticos y dogmáticos.

\section{VigenCIA DE LA CONSTITUCIÓN DE 1925 Y EL "GOLPE DE ESTADO" COMO QUIEBRE INSTITUCIONAL}

Los considerandos de la sentencia del Tribunal Constitucional que tratan sobre la vigencia de la Constitución de 1925 y de 1980 disponen que:

“Trigesimosexto: Que, por otra parte, la Constitución de 1980 no entró en vigencia en todas sus disposiciones el 11 de marzo de 1981. Por aplicación de la Disposición Décimo Tercera y Vigésimo Primera Transitoria, una serie de preceptos permanecieron en suspenso entre 1981 y 1988.

Sin embargo, ninguno de los preceptos que integraban el Capítulo VI de la Constitución (artículos 73 al 80) fueron suspendidos en su vigencia. Por lo mismo, entraron en vigencia el 11 de marzo de 1981;

Trigesimoséptimo: Que, como la Constitución es un texto orgánico nuevo, debe descartarse la vigencia de preceptos de la Constitución de 1925. Esta fue derogada parcialmente primero, a través de una serie de decretos leyes, y luego orgánicamente por la propia Constitución de 1980". 
Trigésimoctavo: Que, por lo mismo, vigente los preceptos, se aplica plenamente el artículo $6^{\circ}$ de la Constitución, que establece que los órganos del Estado deben someter su acción a la Constitución y a las normas dictadas conforme a ellas".

Las reflexiones sobre la vigencia de la Constitución Política de 1925 no se enmarcan solo en lo jurídico, sino que también tocan otros aspectos históricos, políticos y sociales. Una precisión inicial es que la Constitución de 1980, o si se prefiere el Decreto Ley No 3.464, de 1980, adquiere vigencia parcial el 11 de marzo de 1981; según lo disponía el artículo final del instrumento de gobierno: “... seis meses después de ser aprobada mediante plebiscito...”, plebiscito que fue un fraude en toda regla o en términos más asépticos; usando libremente la taxonomía de Nohlen como "no competitivos" (11 de septiembre de 1980)ํ. La vigencia completa de la mencionada Constitución de 1980, merced un plebiscito "semicompetitivo" (5 de octubre de 1988) de continuidad del régimen autoritario (previsto en las Disposiciones Transitorias $27^{\circ}, 28^{\circ}$ y $29^{\circ}$ ) en que la ciudadanía frustra tal posibilidad y a su causa reformada ésta en 1989, y se produce la vigencia del instrumento de gobierno a contar del 11 de marzo de 1990 (no en "1988"). En dicha fecha es cuando en propiedad se inicia la transición a la democracia y la asunción de las autoridades electivas; como lo hace explícita la Disposición Transitoria $21^{\circ}$.

En el interin (11 de marzo de 1981 a 11 de marzo de 1990) tenemos un "derecho constitucional" formal-material de transición del régimen autoritario a una democracia representativa, democracia representativa que, una vez instalada, queda cautiva por un número muy relevante de enclaves autoritarios-institucionales; que sólo vendrán a ser removidos (no completamente) por la reforma constitucional de 2005.

Los decretos leyes iusfundamentales que emanan del poder constituyente del régimen autoritario conforman una unidad jurídica e institucional, un subsistema normativo propio, diferente a la Constitución de 1925, ideado por las fuerzas políticas, juristas e ideólogos de la dictadura militar ${ }^{2}$. En particular es lo que ocurre con los numerosos decretos leyes dictados desde el 11 de septiembre de 1973 en adelante, fruto de un poder constituyente autocrático residenciado en una Junta de Gobierno, expresión orgánica de un régimen autoritario (dictadura cívico-militar) que se había dado su propia legalidad y superlegalidad (D.L. No 1

1 Nohlen, Dieter (1984), pp. 17-18.

2 Silva Bascuñán (1997), p. 164. 
Acta de la Junta de Gobierno de 11 de septiembre de 1973, D.L. No 527 de 1974, D.L. No 788 de 1974 y D.L. No 806 de 1974), colofón de una revolución o "refundación autoritaria" de un capitalismo de nuevo cuño; cuya expresión ideológica en el campo económico y político más perdurable es el "ladrillo" de los economistas neoliberales; que cuajó en una reforma fiscal y en un programa de "modernizaciones"; que son claves para entender nuestro actual capitalismo ${ }^{3}$. No se trata de una revolución de verde oliva, pero es un cambio muy profundo, para algunos una "revolución conservadora".

No habrá por ende continuidad jurídico-fundamental (tampoco la habrá en el derecho público en particular) entre la Constitución de 1925 y la superlegalidad del régimen autoritario; dado que el impropiamente denominado "golpe de Estado" o melifluamente "pronunciamiento militar" es en términos de Kelsen una "revolución" o discontinuidad radical de subsistemas y sistemas normativos.

Este elemento toral de discontinuidad institucional es reconocido por la doctrina de orientación más conservadora, a saber: "interrupción de la continuidad institucional" ${ }^{4}$, y carácter fundacional, que para Cea Egaña se expresa, además de la interrupción, en la creación y modificación de instituciones, un régimen rectificador de hábitos e innovador en los modelos de desarrollo socioeconómico; régimen que se consolida con la dictación del D.L. No 788 que contiene normas relativas al poder constituyente y que buscó resolver definitivamente la compleja situación con las "modificaciones tácitas" a la Constitución de 1925. Al respecto, Alejandro Silva Bascuñán ha señalado que el poder constituyente que se atribuyó la Junta de Gobierno puede entenderse como el instituido o el derivado, compatible con el mantenimiento nominal de su titularidad en el pueblo, dando paso así en tal supuesto a una especie de dictadura comisarial en la terminología de Carl Schmitt; pero a medida que la dictadura castrense se afirmaba en su poder y su voluntad de permanecer en la dirección del país se iba proclamando la naturaleza fundacional y revolucionaria de su verdadera inspiración, una dictadura indiscutiblemente soberana que se va definiendo a través de los textos del D.L. No $1,128,527$ y $788^{5}$.

3 ZÚNiga, Francisco (2013), pp. 523.

4 Cea Egaña, José Luis (2008), pp. 62 y ss.

5 Silva Bascuñán, Alejandro. "Tratado de Derecho Constitucional", Tomo III, Edit. Jurídica de Chile, Santiago, 1997, pp. 240 y ss. 
El abordaje de la cuestión que nos ocupa: la interrupción de la continuidad institucional y del orden constitucional y jurídico debe hacerse identificando en el sistema normativo el binomio legitimidad - efectividad; binomio que nos permite tratar el hecho de la "revolución" o facticidad como la fuente de una nueva "legitimidad-efectividad", sin alterar la continuidad del Estado en el derecho internacional. Luego derecho y revolución no son conceptos "antitéticos" (Linares Quintana); sino en apariencia. La "revolución” se produce cuando el orden jurídico es nulificado, substituido en forma ilegítima por un nuevo orden, evidenciándose así la ruptura en la continuidad constitucional y en el orden jurídico (Kelsen). Con todo, partes significativas del antiguo ordenamiento jurídico pueden subsistir (derecho privado); pero son válidas con base a una nueva norma fundamental del nuevo ordenamiento, produciéndose así la "recepción" parcial de viejo ordenamiento (Bobbio) ${ }^{6}$. Bobbio nos recuerda: "para la teoría del derecho, la revolución significa el momento de la ruptura entre un orden y otro, la terminación, que jurídicamente quiere decir invalidez e ineficacia, del viejo orden, y el principio del nuevo". La revolución implica una modificación de la "norma fundamental", del cimento de validez del orden jurídico; siendo la manera del cambio (movilización social, violencia, crimen) no relevante; lo basal es la "naturaleza del cambio". Ello convierte a la facticidad (revolución y hecho revolucionario) en un "hecho normativo", en un hecho que tiene una doble naturaleza, de ser al mismo tiempo la extinción del antiguo orden y la constitución del nuevo orden. De allí el interés, u obsesión en ocasiones, del jurista por encontrar el "fundamento de legitimidad", aún volcándose al viejo arsenal de la filosofía política clásica y la distinción: legitimidad de origen y legitimidad de ejercicio, o a tomar distancia del despotismo o la tiranía.

En el mismo sentido y a análogas conclusiones se arriban, para evitar o mitigar la fobia antipositivista, al abordar el binomio facticidad-normatividad con otro clásico como Schmitt, que ante el hecho revolucionario (y cambio en el soberano) se produce la "destrucción" constitucional, es decir, un cambio total de la Constitución y un cambio en el propio poder constituyente. La variante antiformalista en la teoría estatal no admitirá en la facticidad una norma fundamental (Grundnorm), sino “...la voluntad del Estado no sometida a normas..." (Heller) ${ }^{7}$

6 KelSen, Hans (1995), pp. 136-14; BobBio, Norberto (1995), pp. 264-265; (2004)"Reforma y Revolución", en recopilación "Norberto Bobbio: el filósofo y la política; Linares Quintana, Segundo" (1956), p. 247.

7 Schmitt, Carl (1985) y (1982); Heller, Hermann (1968). Un inserto en la época (1980), escrito en clave schmittiana, en defensa de la "Constitución" sometida a plebiscito de profesores de derecho de la PUC, 
De esta suerte, en el período que transcurre desde el 11 de septiembre de 1973 al 11 de marzo de 1981 la invocación de la Constitución de 1925 resultaba puramente nominal o absurda; esta había sido destruida; su invocación era ideológica para arropar a la dictadura como la archirrepetida supervivencia de las "atribuciones" del Poder Judicial según ordenaba el Decreto Ley No 1 de 11 de septiembre de 1973 (poder del Estado que se acopló a las nuevas instituciones del régimen autoritario). Este lastre ideológico puede tener algún sentido, si usando la distinción dictadura comisoria-dictadura soberana de Schmitt, se pudiere sostener que la dictadura es inicialmente comisarial, y sólo más tarde, cuando se instala deviene en soberana (Silva Bascunán). Con todo, tiendo a estar más de acuerdo con Cristi en orden a que la dictadura fue siempre soberana, a pesar de los arropamientos o mascaradas continuistas o legitimistas; lo que ocurre es que el solo concepto de "revolución" es ambiguo y perturba al "semántico" por su "carga emocional" (Brinton) ${ }^{8}$.

Por todo ello sostenemos que es una impropiedad dogmática o un ejercicio de logomaquia jurídica entender, como lo hace en el presente el Tribunal Constitucional, que la Constitución de 1925 sí continuaba vigente y que la dictación de la nueva Carta por el constituyente autocrático corresponda a una "derogación", orgánica o "abrogación" como en rigor se denomina a las de este tipo; y que sus modificaciones anteriores eran "derogaciones" fictas o reales como lo dispone el Decreto Ley de blanqueo constitucional. En efecto, la tesis del Tribunal Constitucional de una derogación parcial y sucesiva, primero en el período 1973-1980 y luego una derogación orgánica de la Carta de 1925, es, a mi juicio, además una impropiedad histórico-política.

Lo contrario equivaldría a sostener que la mentada derogación parcial primero y la abrogación posterior serían obra de detentadores de un poder político reos de "sedición", tal cual lo prescribía el artículo $3^{\circ}$ de la Constitución de 1925 para designar a quienes se arrogan poder o autoridad que legítimamente no poseen. Sin perjuicio de que el régimen autoritario hunde su poder político en la revolución o "golpe" triunfante y sus autores son sediciosos (si no, basta leer el artículo $3^{\circ}$

quienes argumentan con inusual realismo o brutalidad que la Junta de Gobierno tenía “... potestad constituyente por haber advenido al poder en virtud de una revolución legítima (...) En consecuencia, reside en los nuevos gobernantes revolucionarios el poder constituyente originario, tanto para el establecimiento de una nueva institucionalidad que automáticamente se crea como concurrencia de la revolución, como para regular transitoria y definitivamente la nueva institucionalidad".

8 Cristi, Renato (2000); Brinton, Crane (1962), pp. 15-16. También, Arendt, Hanna (1988). 
del D.L. No 1 de 1973 de acuerdo al cual la Junta de Gobierno, "respetará la Constitución y las leyes de la República, en la medida en que la actual situación del país lo permitan para el mejor cumplimiento de los postulados que ella se propone...")., lo cierto es que el razonamiento del Tribunal Constitucional al hablar de derogación, expresa una incomprensión teórica frente a la fuerza normativa de la facticidad y de la violencia organizada, y en una perspectiva sistémica a la sucesión de ordenamientos jurídicos en el tiempo marcados por el signo de la discontinuidad o ruptura. En suma, la lectura histórico-jurídica del Tribunal lleva ae desconocer el ascenso y el predominio de la violencia por sobre la sujeción a las reglas constitucionales (existentes) y la pulverización de las mismas por la fuerza del "golpe de Estado" de 1973, asignando un significado político y jurídico inconsistente con lo que fue la conducta de la dictadura cívico-militar, que decidía por sí y ante sí, el ejercicio de su poder de facto.

De ahí que se hace obligado, además, precisar los alcances de la doctrina del "blanqueo constitucional" sostenida por el régimen autoritario y sus juristas afines, y de la que se hace cargo el Decreto Ley No 788, de 1974; doctrina que encubre la realidad como todo ejercicio ideológico. Tal blanqueo es una hipocresía, en palabras de La Rochefoucauld es el tributo que "el vicio rinde a la virtud"; plantearse la vigencia de la Constitución de 1925 más allá del 11 de septiembre de 1973, por lo que los decretos leyes iusfundamentales debían tener la cualidad derogatoria parcial, tácita o expresa del instrumento de gobierno9.

Análogamente es una hipocresía la utilización de la doctrina del gobierno de facto y de la doctrina de facto para conferir cobertura de legitimidad a dictaduras, como lo hizo (con "ostensible complacencia y diligencia" nos recuerda Sánchez Viamonte) la Corte Suprema de la Nación Argentina mediante acordada de 10 de septiembre de 1930, cuando se derroca al presidente Hipólito Yrigoyen. La doctrina del gobierno de facto llegó a hacer uso impropio de la doctrina del

9 El Decreto Ley No 788 que dictó normas sobre el ejercicio del Poder Constituyente, de 2 de diciembre de 1974, señala: "Artículo 1º.- Declárese que los decretos leyes dictados hasta la fecha por la Junta de Gobierno, en cuanto sean contrarios o se opongan, o sean distintos, a algún precepto de la Constitución Política del Estado, han tenido y tienen la calidad de normas modificatorias, ya sea de carácter expreso o tácito, parcial o total, del correspondiente precepto de dicha Constitución.

Artículo $2^{\circ}$.- Aclárese el alcance del inciso $2^{\circ}$ del artículo $3^{\circ}$ del Decreto Ley $N^{o} 128$, de 1973, en el sentido de que las modificaciones a la Constitución Política del Estado que deben formar parte de su texto y entenderse incorporadas a ella, son las modificaciones de carácter expreso". 
"gobierno de facto" y del funcionario de hecho, y con ello a descontextualizar la obra de A. Constantineau y G. Jézé10.

Desde el 11 de septiembre de 1973, día en que se produjo el "golpe de Estado" o hecho revolucionario por el cual se puso fin ilegítimamente y por la fuerza al Gobierno del Presidente Salvador Allende G., y a todo un arreglo institucional democrático representativo, asume la Junta de Gobierno integrada por los comandantes en jefe de diversas ramas de las Fuerzas Armadas y el General Director de Carabineros; expresando su primer acto formal de superlegalidad o "poder constituyente revolucionario" mediante el Decreto Ley No 1, asumiendo de facto el mando supremo de la Nación. Posteriormente a ello, el poder constituyente autoritario dictó diversos decretos leyes que regulaban de forma parcial u orgánicas materias relativas al estatuto del poder que hacen jurídica, política e históricamente imposible sostener que la Carta de 1925 seguía regulando la institucionalidad de nuestro país. El plexo de decretos leyes (incluidas las actas constitucionales $\mathrm{No}_{\text {s. }}$ 1, 2, 3 y 4 de 1976) integran la Constitución material del régimen autoritario.

Asimismo, desde el Decreto Ley No 128 de 16 de noviembre de 1973, que aclara el sentido y alcance del artículo $1^{\circ}$ del Decreto Ley No 1 , dispone que la Junta de Gobierno ya ha asumido desde su constitución el ejercicio de los poderes constituyente, legislativo y ejecutivo y, aun cuando declara en la misma norma que la Constitución y las leyes continúan vigentes $\left(\operatorname{art.} 2^{\circ}\right)$, ello solo dependía del poder constituyente y legislativo que es ejercido por la misma Junta de Gobierno, siendo, como se ha explicado antes, solo una vigencia a todas luces nominal o a lo sumo una recepción de la superlegalidad o de la legalidad anterior; pero basada en los poderes del régimen de facto que alimenta su normatividad de la propia facticidad.

De esta manera, el mentado blanqueo constitucional, a más de cuarenta años después de su formulación, es visto hoy, o bien como el homenaje que la hipocresía rinde a la virtud, o bien simplemente como un ejercicio ideológico desde el "cielo de los conceptos" de los juristas afines al régimen autoritario, que se representan la supervivencia de la Constitución de 1925 más allá del 11 de septiembre de 1973, y que por ende puede ser derogada parcial u orgánicamente.

Pero, hacerse cargo hoy en una sentencia del Tribunal Constitucional del blanqueo constitucional y de las derogaciones de la Constitución de 1925, me-

10 Linares Quintana, Segundo V. (1976), pp. 474-497; SánChez Viamonte, Carlos (1946), p. 97; (1959) a), pp. 133-170; (1959) b), pp. 349-368; (1948) (1957), pp. 531-674; Albert Constantineau (1945). 
rece una última observación crítica. Primero, mirada retrospectivamente esta cuestión del blanqueo constitucional uno podría entenderla como un intento de dar cobertura de legitimidad a un régimen autoritario y un derecho fundamental conformado por un plexo de decretos leyes que no tenían tal legitimidad; pues era inocultable en 1973 el declarado (aparente) objetivo restauracionista del orden, las tradiciones y la institucionalidad por el régimen. Sin embargo, en marzo de 1974 la Declaración de Principios del Gobierno da cuenta de objetivos refundacionales, que hacían innecesario arroparse de la vieja legitimidad, lo que queda en evidencia en los siguientes términos: "Dentro del marco expuesto en el punto anterior, el Gobierno de las Fuerzas Armadas y de Orden ha asumido la misión histórica de dar a Chile una nueva institucionalidad que recoja los profundos cambios que la época contemporánea ha ido produciendo. Solo asi será posible dotar a nuestra democracia de una sólida estabilidad, depurando a nuestro sistema democrático de los vicios que facilitaron su destrucción, pero trascendiendo a una mera labor rectificadora para entrar de lleno en el audaz campo de la creación. Punto capital de esa nueva institucionalidad será la "descentralización de poder, tanto en lo funcional como en lo territorial, lo cual permitirá al país avanzar hacia una sociedad tecnificada y de verdadera participación social'»11.

Probablemente, la doctrina del blanqueo constitucional satisfacía la necesidad de fingimiento o expiar la "culpa" de juristas, letrados, y en general ubicuos servidores públicos adictos a la dictadura. Pero, segundo, con la mirada de presente (2017), que el Tribunal Constitucional admita hoy en un obiter dicta (en la argumentación de mayoría de la decisión judicial) tal posibilidad de supervivencia de la Constitución de 1925 y de sus "derogaciones" es francamente un error inasumible en términos dogmáticos, políticos e históricos.

\section{BiBLIOGRAFÍA CITADA}

Boвbio, Norberto (1995): Teoría General del Derecho, (Madrid, Edit. Debate). Bоввіо, Norberto (2004): "Reforma y Revolución”, en Norberto Bobbio: el filósofo y la política, (México, Fondo de Cultura Económica), 2a edic.

BRINTON, Crane (1962): Anatomía de la Revolución, (Madrid, Editorial Aguilar).

11 Declaración de principios Gobierno de Chile. En: "Ordenamiento Constitucional. Constitución Política de la República. Actas constitucionales. Antecedentes y normas complementarias". Recopilación, notas y concordancias por Soto Kloss, Eduardo, Edit. Jurídica de Chile, Santiago, 1980, pp. 49-50. 
Cea Egaña, José Luis (2008): Derecho Constitucional Chileno, Tomo I, (Santiago, Ediciones Universidad Católica de Chile).

Cristi, Renato (2000): El pensamiento político de Jaime Guzmán. Autoridad y libertad, (Santiago, Ediciones LOM).

Constantineau, Albert (1945): Tratado de la doctrina de facto, (Buenos Aires, Edit. Depalma), 2 vol.

Heller, Hermann (1968): Teoría del Estado, (México, Fondo de Cultura Económica), 6a edición.

Linares Quintana, Segundo (1956): Tratado de la Ciencia del Derecho Constitucional Argentino y Comparado, (Buenos Aires, Edit Plus Ultra), 7 tomos.

Linares Quintana, Segundo (1976): Derecho Constitucional e Instituciones Políticas. Teoría empirica de las instituciones políticas, (Buenos Aires, Edit. Plus Ultra), 3 vol.

Kelsen, Hans (1995): Teoría General del Derecho y del Estado, (México, Edit. UNAM).

Nohlen, Dieter (1984): Elecciones y sistemas electorales, (República Federal de Alemania, FES).

Sánchez Viamonte, Carlos (1946): Revolución y doctrina de facto, (Buenos Aires, Edit. Claridad), Buenos Aires.

Sánchez Viamonte, Carlos (1948): Historia Institucional de Argentina, (México D.F. Edit. Fondo de Cultura Económica.

Sánchez Viamonte, Carlos (1957): El constitucionalismo. Sus problemas, (Buenos Aires, Edit. Bibliográfica Argentina).

Sánchez Viamonte, Carlos (1959) a): Manual de Derecho Político. Los problemas de la democracia, (Buenos Aires, Edit. Bibliográfica Argentina).

Sánchez Viamonte, Carlos (1959) b): Manual de Derecho Constitucional, (Buenos Aires, Edit. Kapelusz), $4^{\text {a }}$ edición.

Schmitt, Carl (1982): Teoría de la Constitución, (Madrid, Edit. Alianza).

Schmitt, Carl (1985): La dictadura, (Madrid, Edit. Alianza).

ZÚNIGA, Francisco (2013): "Nueva Constitución y operación constituyente. Algunas notas acerca de la reforma constitucional y de la asamblea constituyente". En: Estudios Constitucionales, No 1, Año 11. 